\title{
MEGAURETER TREATED WITH MYCOPHENOLATE MOFETIL IN PATIENT WITH SYSTEMIC ERITHEMATOSUS LUPUS: CASE REPORT
}

\author{
Jady Elen de Pontes ${ }^{1, *}$, Thelma L. Skare ${ }^{1}$, Thiago Alberto F. G. dos Santos ${ }^{1}$ \\ 1. Hospital Universitário Evangélico Mackenzie, Curitiba (PR), Brazil. \\ *Corresponding author: drajadypontes@gmail.com
}

\section{BACKGROUND}

Dilated dysfunction involving multiple visceral organs has been reported in patients with systemic lupus erythematosus (SLE). Usually the visceral muscle dysmotility syndrome (VMDS) is described as the presence of chronic intestinal pseudo-obstruction (CIPO) in conjunction with ureterohydronephrosis and, more rarely, biliary dilatation (megacholedochus). The presence of isolated ureterohydronephrosis is rare and the treatment is uncertain. In cases of VMDS, there are reports of corticosteroid use, mycophenolic acid, human immunoglobulin, and cyclophosphamide. The objective was to describe a case of megaureter in a patient with SLE successfully treated with mycophenolate mofetil.

\section{CASE REPORT}

The patient was female, 31 years old, on treatment for SLE since 2007. On a routine consult, in September 2019, presented with an increased level of serum creatinine and a normal level serum of urea. Initially, the hypothesis of lupus nephritis was made, but there was no proteinuria on 24 hours urine or other signs of glomerulonephritis. Further investigation showed severe bilateral hydronephrosis on a urologic computerized tomography with no signs of obstruction. The case was taken to the mensal meeting with nephrology service of the hospital where was suggested more complementary images to rule out other causes of secondary obstruction such as tumors. The abdomen magnetic resonance imaging (MRI) shown no signs of intrinsic or extrinsic obstruction and had ureteral hydronephrosis still. The diagnosis hypothesis of megaureter by SLE was made and the patient was treated with mycophenolate mofetil two grams daily plus prednisone $0.5 \mathrm{mg} / \mathrm{kg} /$ day in December 2019. After five months of treatment, in May 2020, a new MRI was made and there was no evidence of hydronephrosis. The serum level of creatinine decreased almost to normal level.

\section{CONCLUSION}

Despite its rarity, megaureter should be included in the causes of increased serum level of creatine in patients with diagnosis of SLE. In this patient, good response to immunosuppressors was observed. 